\title{
LIGHTWEIGHT MODULAR STEEL FLOOR SYSTEM FOR RAPIDLY CONSTRUCTIBLE AND RECONFIGURABLE BUILDINGS
}

\author{
EUGENE BOADI-DANQUAH ${ }^{1}$, BRIAN ROBERTSON ${ }^{1}$, MATTHEW FADDEN ${ }^{1}$, \\ ELAINA J. SUTLEY ${ }^{1} \&$ JOE COLISTRA ${ }^{2}$ \\ ${ }^{1}$ Department of Civil, Environmental, and Architectural Engineering, University of Kansas, \\ United States of America. \\ ${ }^{2}$ Architecture Department, University of Kansas, United States of America.
}

\begin{abstract}
Rapid construction, modularity, deconstruction, and reconfiguration facilitate economy and sustainability allowing for changes in a building's use over time. Typical one-way composite steel/concrete floor systems lend themselves to terminal construction practices that make assumptions about the occupancy and usage needs that must last through the life of the structure. To address this, a lightweight rapidly constructible and reconfigurable modular steel floor (RCRMSF) system that utilizes two-way bending behavior and cold-formed steel building materials has been developed. RCRMSF improves upon the efficiency benefits of traditional composite steel/concrete flooring systems, reducing beam and girder usage and size, and allowing for highly flexible building configurations and mobility. The system consists of a series of prefabricated panels composed of a grid of cold-formed steel channels running in orthogonal directions sandwiched together by steel plates. A simple performance assessment has been formulated and a finite element model parametric study has been carried out in the Abaqus finite element analysis (FEA) software. The results of the developed performance assessment and FEA study show that RCRMSF systems are suitable for rapidly constructible buildings in terms of strength and serviceability, providing an initial step to fully modular and reconfigurable steel buildings.

Keywords: design for reuse, finite element analysis, innovative steel structures, modular buildings, rapid construction, steel floors.
\end{abstract}

\section{INTRODUCTION}

As natural resources become scarcer, structural engineering must find sustainable design methodologies to reduce material usage. At the same time, structures must remain resilient to economic changes and the effects of extreme loads such as earthquakes. While most buildings remain static, rapidly constructible and movable building structures provide a new paradigm that can address these needs. These structures require modularity, reconfigurability, rapid constructability and integration of mechanical, electrical and plumbing systems $(\mathrm{M} / \mathrm{E} / \mathrm{P})$. No currently known system has all these characteristics. These attributes provide both economic and life-safety resilience. If building use needs to change to meet market needs, the system can adapt quickly for reuse or be deconstructed, moved, and reconstructed for reuse at a different location. Likewise, if an extreme event takes place a resilient system will show reduced damage and have the ability to replace modular components if necessary. It is envisioned that the structures of the future will be completely movable with limited site preparation using modular and rapidly constructible design and construction practices. Rapidly constructible and reconfigurable modular steel floor (RCRMSF) systems will play a key role in these kit-of-part systems.

One of the many barriers to making movable and rapidly constructible steel structures are typical one-way composite steel/concrete floor systems pervasive to commercial, residential, and industrial construction. A multitude of flooring systems, [1-4], have been developed to improve upon the performance of the standard flooring system including systems that 
consider Design for Deconstruction (DfD) [5, 6]. Regardless, one-way composite floors result in large gravity loads and high inertial forces that lead to unnecessary material usage and damage during extreme events. Limited research has been focused on analyzing and developing lighter floor systems for steel structures, considering the two-way bending behavior $[7,8]$. Two-way steel systems are possible and show promising results, but they have not been implemented during construction.

While movable and modular structures are not currently popular in the United States, a recent study among architects, engineers, general contractors, and owners found that construction speed, reduced costs, site safety, and quality can be improved with modular construction [9]. At the same time, material waste and impact on the environment can be reduced creating more sustainable buildings [9]. Currently, many prefabricated building components are already available; however, lightweight, integrated, and reconfigurable building components, especially floor systems, are limited or non-existent.

In an attempt to increase the suitability and utility of these building components for construction, the development of the RCRMSF system addresses many of the limitations to the current state-of-the-art. RCRMSF's are envisioned to be one of many rapidly constructible, modular building components that are designed to integrate M/E/P and non-structural systems and use advanced analysis methods such as two-way action, allowing for adaptable building structures of the future. RCRMSF's by design increase the versatility of structural systems, improve integration of non-structural components, allow for modular construction, and use new detailing to enhance constructability, economy, and resiliency. Additionally, as few assumptions as possible about the future use of the RCRMSF's are considered such that a robust and versatile system is achieved.

This paper focuses on the development of the RCRMSF for rapidly constructible and reconfigurable structures. A strength and serviceability analysis procedure was developed for preliminary design and a finite element model parametric study was carried out to predict and understand RCRMSF system performance. The results of this research will lead to design recommendations and construction procedures for the next generation of highly adaptive building structures.

\section{RCRMSF CONCEPT AND DESIGN}

\subsection{RCRMSF description}

The RCRMSF system is just one building component of future integrated modular structures. The RCRMSF system is comprised of individual rectangular panels fabricated from thingauge steel top and bottom plates with a sandwiched grillage of cold formed channels, Fig. 1. To form the grillage, channels are placed in an orthogonal arrangement with even spacing. Fig. 2 shows the profiling that is used to allow the channels to meet this configuration within each panel. The channels can be further detailed to allow for integration of M/E/P components during fabrication. Self-drilling self-tapping screws are used to connect the plates to channels. The floor is topped with a thin layer of gypsum concrete to aid in fire proofing, acoustics, and finishing.

As shown in Fig. 1, the RCRMSF panels can be shipped to the construction site, lifted into the skeleton structure, and rapidly constructed with web splices and cover plates using screw connections. As previously described, RCRMSFs are designed such that the structure can be deconstructed, moved or reconfigured, and reconstructed. This is achieved through simple 


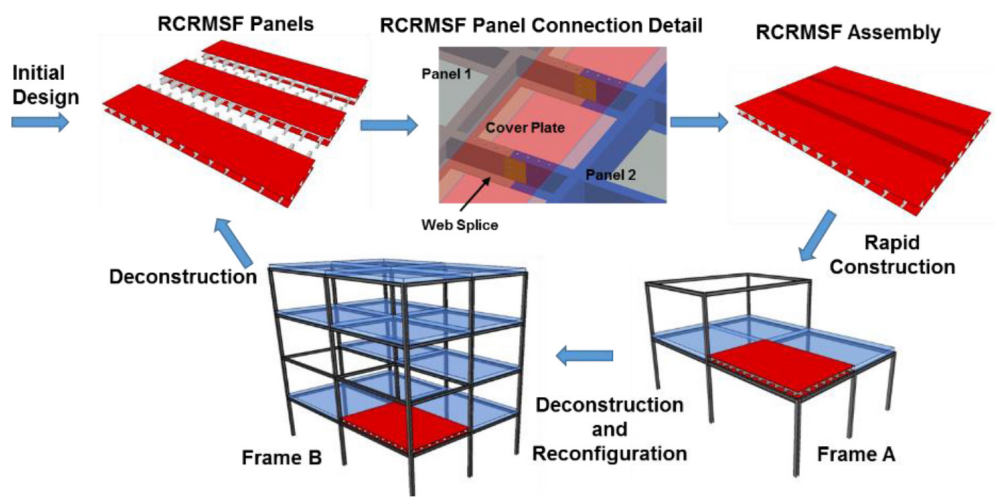

Figure 1: RCRMSF system concept.

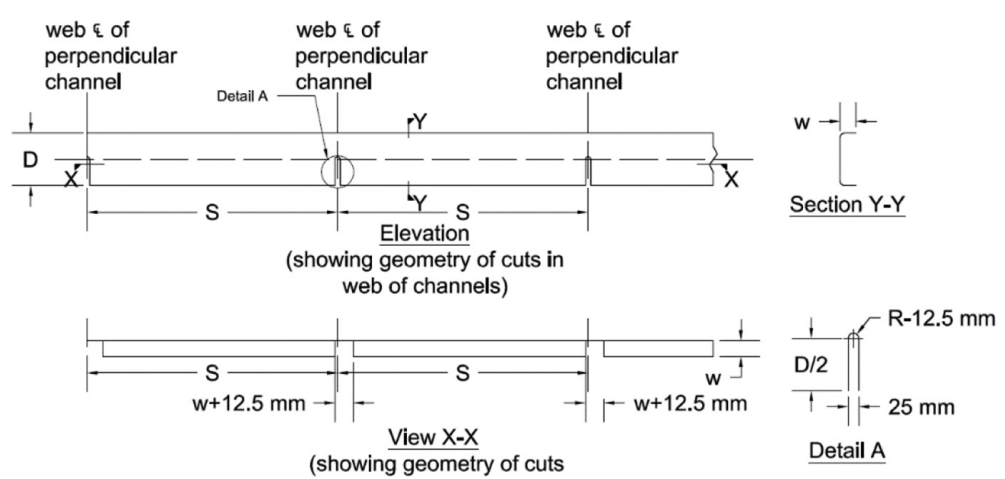

Figure 2: Details of channel cut-outs.

unscrewing of the panels and rapid construction in a new structure (i.e. Frame A to Frame B). If no longer needed, the panels can be taken down to make space until needs change. Overall, this design creates a highly adaptable flooring system.

\subsection{Performance assessment}

The procedure for assessing the structural performance of RCRMSF is formulated based on three failure limit states: (1) excessive deflection, (2) yielding of sandwich plates and (3) failure of connectors at the interface between plates and channels. This assessment considers the monolithic performance of the constructed panel within a structural bay ignoring the panel connection detail.

\subsubsection{Deflection assessment}

Allowable deflections of the RCRMSF are bounded by limits set in the International Building Code (IBC) [10]. For floor members, the deflection shall not exceed $l / 360$ for live loads or $l / 240$ for a combination of live and dead loads, where $l$ represents the short span of the assembled deck. 
Estimation of the system's deflection under service loads is based on the plate bending theory by Timoshenko and Woinowsky-Krieger [11]. The deflection of a simply supported rectangular plate under uniform loading is expressed as;

$$
\begin{gathered}
\Delta_{\max }=\alpha \frac{q a^{4}}{F} \\
F=\frac{E h^{3}}{12\left(1-v^{2}\right)}
\end{gathered}
$$

where $\Delta_{\max }$ is the maximum displacement, $\alpha$ is a coefficient dependent on the aspect ratio (longer span, $b$ to shorter span, $a$ ) and $q$ is the pressure loading. $F$ represents the flexural rigidity, estimated using eqn. (2) for a rectangular plate with thickness, $h$, elastic modulus, $E$, and Poisson's ratio, $v$.

For the equations above to be applicable to the RCRMSF, the flexural rigidity has been modified to account for the use of the plate pair and the stiffness contributions from the channels in the two orthogonal directions. The result is a modified flexural rigidity, expressed as;

$$
\begin{gathered}
F_{\text {mod }}=\frac{E\left(H^{3}-D^{3}\right)}{12\left(1-v^{2}\right)} \\
H=D+2 t_{m}
\end{gathered}
$$

where $D$ is the overall height of channel (space between the plates) and $t_{m}$ is the thickness of the plate, modified to account for the stiffness contribution of the sandwiched channels. The contribution of the layer of gypsum concrete to the system stiffness is ignored in this assessment as it is not used for strength purposes.

\subsubsection{Plate yielding assessment}

The process of assessing the ultimate load of the RCRMSF is based on plate yield line theory. The application of the yield line theory for this assessment involves the utilization of the primary collapse mechanisms as shown in Fig. 3. The ultimate collapse load is obtained by equating the external work done by an applied load, $q$, to the internal work done in rotating yield lines. For efficiency in this system, it is desirable for no plate yielding to occur up to the deflection limits.

\subsubsection{Connector design}

Screw connectors are provided to transfer the full shear at the interface between the plates and channel up to the point where the plates fully yield as such connector failure does not govern the assessment and performance of the system. The shear capacity of each connector, $Q_{n}$ is determined in accordance with the provisions of section E4.3 of AISI S100 [12]. The capacity of the total number of connectors provided is required to exceed the total force required to fully yield the plate, $F_{s}$.

The magnitude of $F_{s}$ depends on the yield strength of the steel, $f_{y}$, the thickness of the steel plate, $t_{p}$ and the spacing between the channels, $\mathrm{s}$, and is computed as

$$
F_{s}=f_{y} \mathrm{st}_{\mathrm{p}}
$$




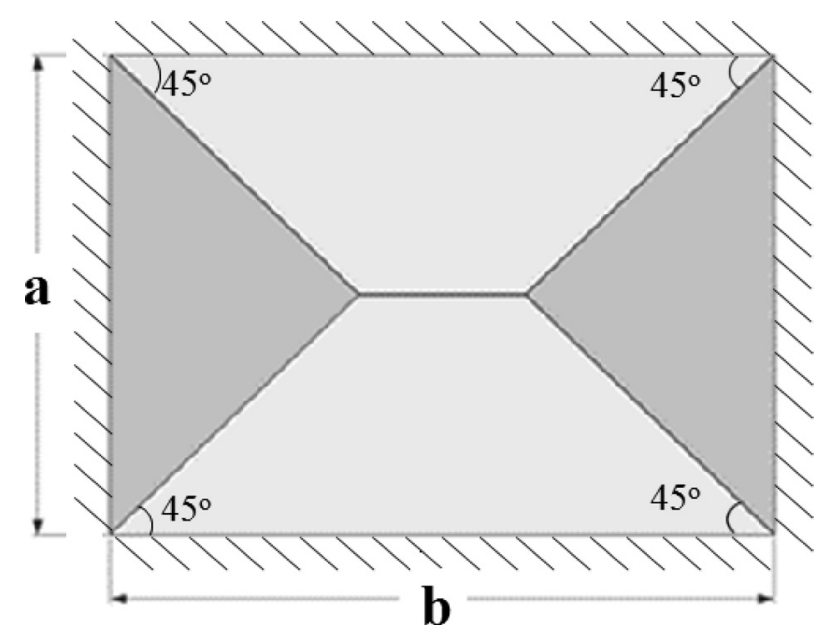

Figure 3: Yield line analysis collapse mechanism.

$\Sigma Q_{n}$ therefore should exceed $F_{s .}$ The total number of connectors is determined for shear transfer in the (shorter) stiffer direction only, and spaced to evenly cover the two orthogonal directions.

\section{FINITE ELEMENT ANALYSIS PARAMETRIC STUDY}

Finite element models were created to assess the strength and serviceability performance of the system, and a parametric study carried out to assess the effects of varying certain critical parameters on the performance of the system. For this study, the FEA models considered a monolithic panel and did not account for connectors which splice the individual panels of the RCRMSF.

\subsection{Description of finite element model}

The finite element models were generated in Abaqus FEA (Version 6.14) [13] to support the performance assessment formulated earlier and to study the influence of different parameters on the strength of the system. The geometry of the steel component, including the width $(w)$, depth $(D)$, and thickness $(t)$, was taken as that reported in the SSMA Product Technical Guide (Fig. 4a) [14]. Additionally, the fastener details were taken from Hilti Product Technical Guide [15]. Steel gages studied with their equivalent minimum thicknesses and inside bend radii (for channels) are as summarized in Table 1.

The plates, channels and gypsum concrete topping were modeled using 3-D shell elements. The material properties of the steel components were assumed isotropic with an elastic modulus $E=200 \mathrm{GPa}(29,000 \mathrm{ksi})$ and Poison's ratio $v=0.30$. For this nonlinear analysis, an elastic-perfectly plastic material behavior was assumed, with yield stress defined as $\sigma_{y}=345 \mathrm{MPa}(50 \mathrm{ksi})$. The gypsum concrete topping was assumed to be isotropic with a linear elastic behavior and an elastic modulus of $E=11.7 \mathrm{GPa}(1,700 \mathrm{ksi})$. The value was selected to limit the structural contribution of the gypsum concrete to the overall stiffness of 
Table 1: Steel gages with equivalent minimum thicknesses and bending radii.

\begin{tabular}{lll}
\hline Steel Gage & $\begin{array}{l}\text { Minimum thickness, } \\
t(\mathrm{~mm})\end{array}$ & $\begin{array}{l}\text { Inside bend radius, } \\
r(\mathrm{~mm})\end{array}$ \\
\hline 16 & 1.37 & 2.16 \\
14 & 1.72 & 2.72 \\
12 & 2.45 & 3.87 \\
\hline
\end{tabular}

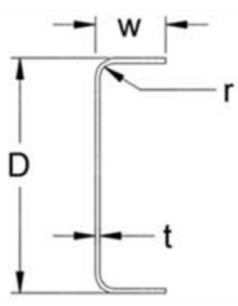

(a) Channel Dimensions

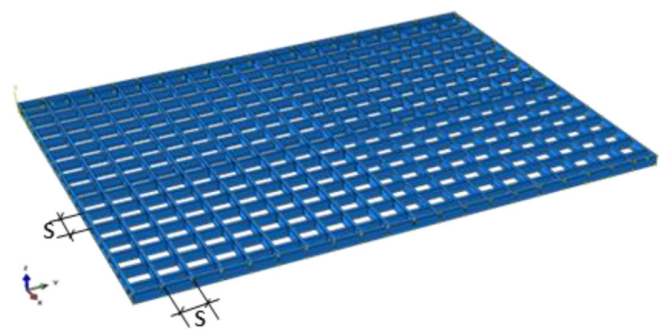

(b) Typical Channel Layout

Figure 4: Typical section geometry of channel and channel layout showing typical spacing (s) of $610 \mathrm{~mm}(2 \mathrm{ft})$.

the system. Its inclusion in the model however ensures uniform load distribution across the top plate without inducing local displacements (depressions) within the channel grid spaces (Fig. 4b). Within all regions, 4-node thin or thick shell elements (S4R) with reduced integration, hourglass control, and considering finite member strains were used.

The element mesh sizes were selected to balance accuracy and efficiency of the model. The top and bottom plates were modeled using rectangular elements of approximately $50 \mathrm{~mm}$ square. The lightweight concrete topping was modeled using rectangular elements of approximately $100 \mathrm{~mm}$ square and the channels were modeled using mixed quad dominated elements of approximately $40 \mathrm{~mm}$ square size. Screw connectors at the interface between the steel plates and channels were specified using mesh independent point fasteners, with sections assembled as "beam type" connectors. In all cases, the numbers of point fasteners specified meet or exceed the minimum number required for full shear transfer. The steel-to-steel contact in the model was defined as hard normal contact with allowance for separation and the tangential behavior defined using a friction coefficient of 0.35 . The interaction between the gypsum concrete topping and the steel top plate was defined using a tie constraint.

Boundary conditions were applied to represent a rectangular deck, simply supported along all four sides, spanning $9.1 \mathrm{~m} \times 12.2 \mathrm{~m}$. By definition, the global $\mathrm{X}, \mathrm{Y}$ and $\mathrm{Z}$ axes of the models represent the transverse, longitudinal and vertical directions of the flooring system, respectively. Translation in the Z-direction was restrained along all four edges of the bottom plate. Additionally, X-translation was restrained along one longitudinal edge, and Y-translation restrained at a single corner node to prevent rigid body motion, without consequently developing horizontal reactions. 


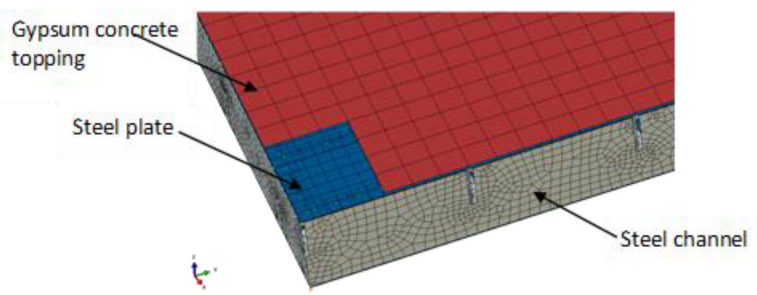

Figure 5: Finite elements part model showing mesh regions.

A uniform pressure was applied over the surface of the gypsum concrete topping. The loading was applied with a ramp type amplitude starting from zero load. For this study, peak loads were recorded after analysis, as the load along the ramp at which the last converging solution was obtained.

\subsection{Parametric study and results}

These studies were conducted to investigate the influence of four parameters, including: plate thickness $\left(t_{p}\right)$, channel thickness $\left(t_{c}\right)$, channel depth $(D)$ and channel spacing $(s)$, on strength characteristics of the system. The range of the parameters considered for service load conditions are represented in Table 2.

A base model with $t_{p}=1.37 \mathrm{~mm}, t_{c}=1.72 \mathrm{~mm}, D=254 \mathrm{~mm}$ and $s=610 \mathrm{~mm}$ was created. The parameters, including the plate thickness $\left(t_{p}\right)$, the channel thickness $\left(t_{c}\right)$, the depth of the channel $(D)$ and the channel spacing (s) were varied as shown in Table 2 . In all cases, the width $(w)$ of the channel flange was kept constant at $76.2 \mathrm{~mm}(3 \mathrm{in})$.

For all the models studied, the peak load was recorded as the load value at which the web of the perimeter channels buckled due to support reactions. Since the higher the magnitude

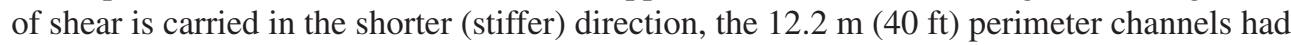
a higher susceptibility to buckling at the supports.

\subsection{RCRMSF Performance}

In order to assess the strength performance of the system, the results of the parametric study were interpreted and compared to results based on the formulated performance assessment to validate the anticipated response of the system to static loading.

From the parametric study, typical load-displacement curves and failure mode can be seen in Fig. 6. Table 3 and Fig. 7 report results from parametric study. The highest peak load

Table 2: Range of parameters considered for FE modelling.

\begin{tabular}{|c|c|c|c|c|c|c|c|c|}
\hline \multicolumn{9}{|c|}{ CHANNELS } \\
\hline \multicolumn{2}{|l|}{ Depth, D (mm) } & 203 & \multicolumn{5}{|c|}{254} & 305 \\
\hline \multicolumn{2}{|c|}{ Spacing, $\mathrm{s}(\mathrm{mm})$} & 610 & \multicolumn{3}{|c|}{610} & \multirow{2}{*}{$\begin{array}{l}1220 \\
1.72\end{array}$} & \multirow{2}{*}{$\frac{1830}{1.72}$} & 610 \\
\hline Thickness, $\mathrm{t}(\mathrm{mm})$ & $t_{t p} t c$ & 1.72 & 2.45 & 1.72 & 1.37 & & & 1.72 \\
\hline \multirow{3}{*}{ 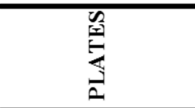 } & 2.45 & & & & & & & \\
\hline & 1.72 & & & & & & & \\
\hline & 1.37 & & & & 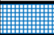 & & & \\
\hline
\end{tabular}

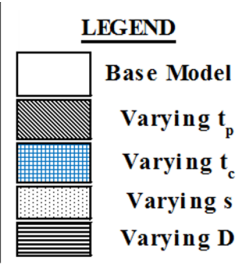



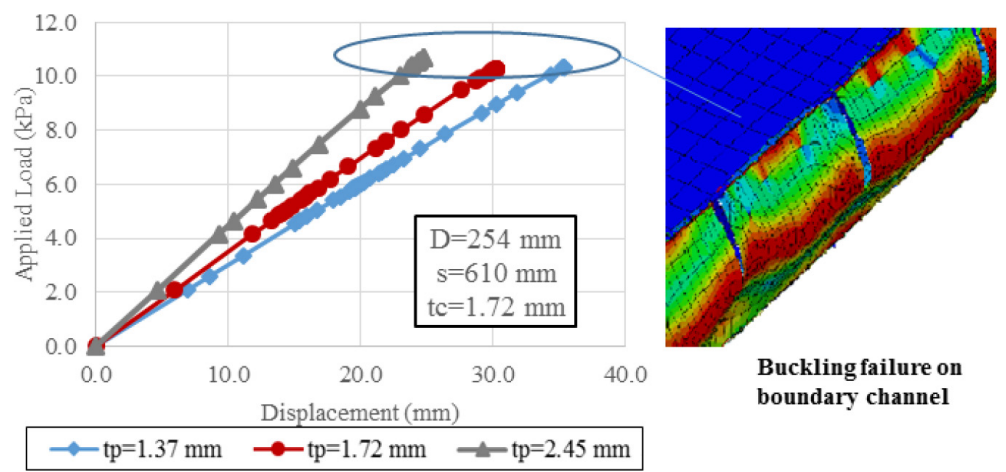

Figure 6: Typical load vs displacement plot (varying plate thickness).

Table 3: Comparison between estimated displacements at $2.4 \mathrm{kPa}$, collapse load based on Yield Line Analysis, and FE model results.

\begin{tabular}{|c|c|c|c|c|c|c|c|}
\hline $\begin{array}{l}\text { Plate } \\
\text { Thickness } \\
t_{p} \\
(\mathrm{~mm})\end{array}$ & $\begin{array}{l}\text { Channel } \\
\text { Thickness } \\
t_{c} \\
(\mathrm{~mm})\end{array}$ & $\begin{array}{l}\text { Channel } \\
\text { Depth } \\
D \\
(\mathrm{~mm})\end{array}$ & $\begin{array}{l}\text { Channel } \\
\text { Spacing } \\
s \\
(\mathrm{~mm})\end{array}$ & $\begin{array}{l}\text { Theo. } \\
\text { Disp. } \\
\Delta_{2.4} \\
(\mathrm{~mm})\end{array}$ & $\begin{array}{l}\text { FE } \\
\text { Model } \\
\text { Disp. } \\
(\mathrm{mm})\end{array}$ & $\begin{array}{l}\text { Yield } \\
\text { Line } \\
\text { Peak } \\
(\mathrm{kPa})\end{array}$ & $\begin{array}{l}\text { FE } \\
\text { Peak } \\
\text { Load } \\
(\mathrm{kPa})\end{array}$ \\
\hline 1.37 & 1.72 & 254 & 610 & 9.14 & 7.96 & 34.10 & 10.34 \\
\hline 1.72 & 1.72 & 254 & 610 & 7.54 & 6.86 & 41.09 & 10.29 \\
\hline 2.45 & 1.72 & 254 & 610 & 5.51 & 5.40 & 55.68 & 10.68 \\
\hline 1.37 & 1.37 & 254 & 610 & 9.50 & 8.25 & 32.68 & 6.00 \\
\hline 1.37 & 2.45 & 254 & 610 & 8.48 & 7.53 & 36.92 & 10.52 \\
\hline 1.37 & 1.72 & 203 & 610 & 14.45 & 11.91 & 26.89 & 6.70 \\
\hline 1.37 & 1.72 & 305 & 610 & 6.27 & 5.78 & 41.52 & 8.42 \\
\hline 1.37 & 1.72 & 254 & 1,220 & 10.11 & 9.14 & 29.77 & 4.55 \\
\hline 1.37 & 1.72 & 254 & 1,830 & 10.47 & 10.34 & 28.77 & 3.16 \\
\hline
\end{tabular}

recorded was $10.68 \mathrm{kPa}$ for the floor with $t_{p}=2.45 \mathrm{~mm}, t_{c}=1.72 \mathrm{~mm}, D=254 \mathrm{~mm}$ and $s=610 \mathrm{~mm}$. The lowest peak load recorded was $3.16 \mathrm{kPa}$ for $t_{p}=1.37 \mathrm{~mm}, t_{c}=1.72 \mathrm{~mm}$, $D=254 \mathrm{~mm}$, and $s=1,830 \mathrm{~mm}$. For all variations in parameters, the perimeter channels buckled at the peak loads as shown on Fig. 6. The highest displacement at $2.4 \mathrm{kPa}\left(\Delta_{2.4}\right)$ was recorded as $11.91 \mathrm{~mm}$ for $t_{p}=1.37 \mathrm{~mm}, t_{c}=1.72 \mathrm{~mm}, D=203 \mathrm{~mm}$, and $s=610 \mathrm{~mm}$. The lowest displacement at $2.4 \mathrm{kPa}\left(\Delta_{2.4}\right)$ was recorded as $5.4 \mathrm{~mm}$ for $t_{p}=2.45 \mathrm{~mm}, t_{c}=1.72 \mathrm{~mm}$, $D=254 \mathrm{~mm}$, and $s=610 \mathrm{~mm}$.

Increasing $t_{p}$ from $1.37 \mathrm{~mm}$ to $1.72 \mathrm{~mm}$ resulted in a reduction in displacement by $1.1 \mathrm{~mm}$, compared to a reduction of $0.28 \mathrm{~mm}$ for increasing $t_{c}$ by the same magnitude, at $2.4 \mathrm{kPa}$ load, holding $s$ and $D$ constant, Fig. 7a. Similarly, increasing $t_{p}$ from $1.72 \mathrm{~mm}$ to $2.45 \mathrm{~mm}$ resulted in a reduction in displacement of $1.46 \mathrm{~mm}$, compared to a reduction of $0.43 \mathrm{~mm}$ for increasing $t_{c}$ by the same magnitude at $2.4 \mathrm{kPa}$ load. As expected, for the spacing considered and constant channel depth, the thickness of the steel plates had a greater influence on the overall 

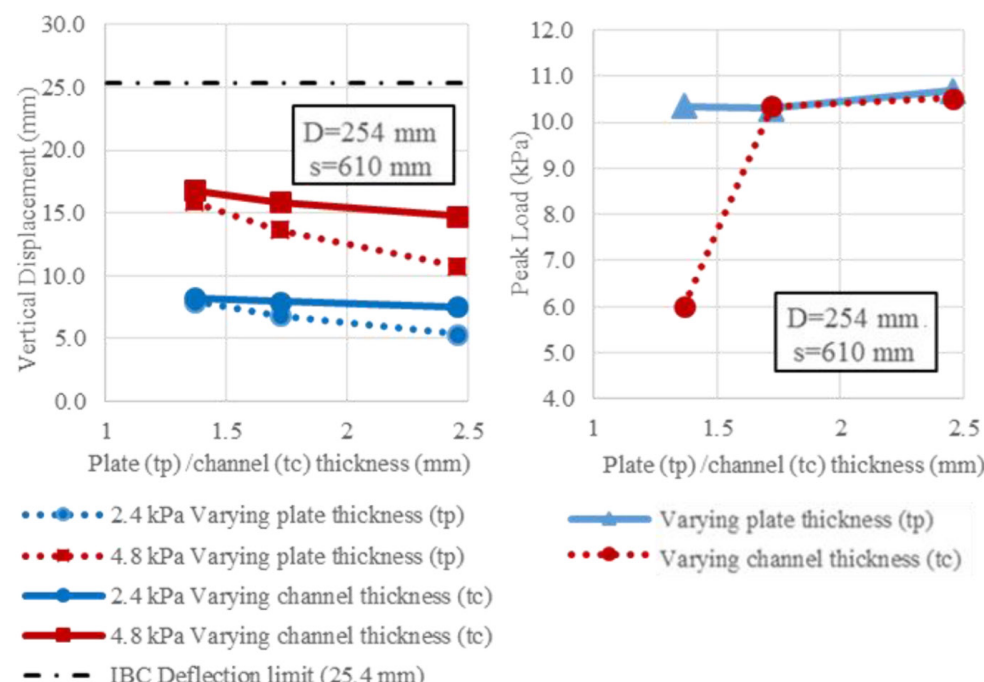

(b)
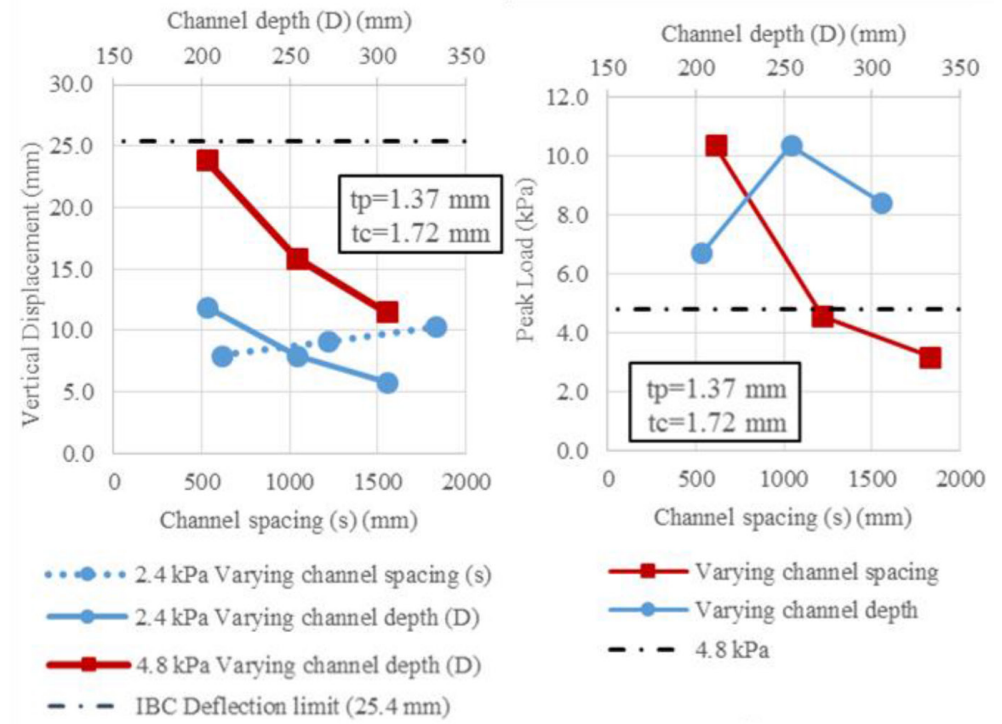

(c)

(d)

Figure 7: Parametric study results; (a) displacements varying $t_{p}$ and $t_{c}$ (b) peak load recorded varying $t_{p}$ and $t_{c}$ (c) displacements at loads varying $s$ and $D(\mathrm{~d})$ peak load recorded varying $s$ and $D$.

stiffness of the system than the thicknesses of the channels due to their larger influence on the moment of inertia.

It was observed that the recorded peak loads were similar for varying plate thickness, Fig 7b. An increase in $t_{c}$ from $1.37 \mathrm{~mm}$ to $1.72 \mathrm{~mm}$, however resulted in an increase in peak load by $4.34 \mathrm{kPa}$. A further increase of $0.18 \mathrm{kPa}$ was recorded for $t_{c}$ increase from $1.72 \mathrm{~mm}$ to $2.45 \mathrm{~mm}$. This indicated that, increasing the wall thickness of the channel 
had a greater influence on the recorded peak loads, due to buckling of thin walls at the support.

Only a minor reduction in system stiffness from increasing the channel spacing $(s)$ from $610 \mathrm{~mm}$ to $1,830 \mathrm{~mm}$ was observed based on an increase in deflection of $2.38 \mathrm{~mm}$ at $2.4 \mathrm{kPa}$ loading, Fig. 7c. The highest peak loads at channel spacings (s) of 1,220 mm and 1,830 mm were less than $4.8 \mathrm{kPa}$, hence variations in system deflections at $4.8 \mathrm{kPa}$ were not plotted. Increasing channel depths $(D)$, with all other parameters kept constant, resulted in an increase in the system's stiffness as a result of the corresponding increase in the system's flexural rigidity.

A peak load drop of $5.8 \mathrm{kPa}$ was observed from increasing channel spacing $(s)$ from $610 \mathrm{~mm}$ to $1,220 \mathrm{~mm}$ and a further drop of $1.4 \mathrm{kPa}$ from increasing from $1,220 \mathrm{~mm}$ to $1,830 \mathrm{~mm}$, Fig. $7 \mathrm{~d}$. This was a direct result of a proportional increase in the shear load taken by the perimeter channels, increasing their susceptibility to buckling. Reducing the depth of the channel from $305 \mathrm{~mm}$ to $254 \mathrm{~mm}$ with all other parameters constant, resulted in an increase in the peak load from $8.42 \mathrm{kPa}$ to $10.34 \mathrm{kPa}$. This is due to the fact that the $305 \mathrm{~mm}$ deep channel is more slender, thus more susceptible to web buckling. Reducing the channel depth further from $254 \mathrm{~mm}$ to $203 \mathrm{~mm}$ reduced the peak load from $8.42 \mathrm{kPa}$ to $6.70 \mathrm{kPa}$. The change in trend was due to the fact that the reduction in depth resulted in a reduced system stiffness and consequently, higher rotations in the top plate, resulting in buckling in the perimeter channels at a lower load.

Comparison of the system's displacement at $2.4 \mathrm{kPa}(50 \mathrm{psf})$ and estimated loads using the formulated design procedure to the results from the finite element parametric studies is as shown in Table 3. It was observed that, while the gypsum concrete was included in the models in order to limit local displacements in the top plate, its contribution to the overall stiffness of the floor became more significant with lower plate thicknesses and shallower deck depth. This was seen in a difference of $2.54 \mathrm{~mm}$ between the estimated displacement and displacement recorded from the FE model for the $t_{p}=1.37 \mathrm{~mm}$ and $D=203 \mathrm{~mm}$ channel depth. For $s=1,830 \mathrm{~mm}$, more significant shear load was transferred to the perimeter channels and they began to buckle at a load below $2.4 \mathrm{kPa}$ causing some plastic deformation in addition to the plate's elastic displacement. These additional plastic deformations offset the stiffness contribution of the lightweight concrete, resulting in the "false" agreement between the two values, differing only by $0.13 \mathrm{~mm}$.

In all cases, a lower peak load was recorded from the FE models compared to the load estimated using yield line analysis. The highest difference in load is for the plate thickness of $2.45 \mathrm{~mm}$, where the estimated collapse load from yield line analysis was $55.68 \mathrm{kPa}$ compared to a load of $10.68 \mathrm{kPa}$ from the FE model. This disparity is a result of the channels buckling around the perimeter well ahead of the onset of plate yielding.

\section{CONCLUSIONS AND RECOMMENDATIONS}

In this study, a novel RCRMSF system was developed. A performance assessment was undertaken and verified through a parametric finite element analysis (FEA). The parametric studies found that steel plate thickness, channel thickness, channel depth, and channel spacing each had a distinct effect on system performance.

Overall, the RCRMSF has shown an adequate strength capacity to support live loads in excess of $2.4 \mathrm{kPa}$ (50 psf), recommended for office use in accordance with the International Building Code (IBC) [10]. Higher strength capacities are attainable with the right selection of the parameters that control the stiffness and load response of the system. It is recommended 
that in order to utilize the full capacity of the top and bottom plates, channels should be optimally sized and spaced to reduce buckling prior to the onset of plate yielding. Alternatively, extra perimeter reinforcement can be used to reduce the effects of web buckling on the system prior to plate yielding. Overall, the RCRMSF system provides a suitable alternative to the typical design and construction of steel structures and allows for rapid, modular construction.

\section{ACKNOWLEDGEMENT}

This research was made possible by the American Institute of Steel Construction Milek Faculty Fellowship. The views expressed herein are solely those of the authors and do not necessarily represent the views of the supporting agency.

\section{REFERENCES}

[1] Colaco, J.P., Stub-girder system for high-rise buildings. Engineering Journal-American Institute of Steel Construction Inc, 9(3), pp. 89-95, 1972.

[2] Girder Slab. Girder Slab Composite Steel and Precast System, available at: www. girder-slab.com

[3] Hanaor, A., Tests of composite beams with cold-formed sections. Journal of Constructional Steel Research, 54(2), pp. 245-264, 2000. https:/doi.org/10.1016/S0143-974X(99)00046-2

[4] Hsu, C-T., Punurai, S. Punurai, W. \& Majdi, Y., New composite beams having coldformed steel joists and concrete slab. Engineering Structures, 71, pp. 187-200, 2014. https:/doi.org/10.1016/j.engstruct.2014.04.011

[5] Wang, L., Webster, M.D. \& Hajjar, J.F., Behavior of deconstructable steel-concrete shear connection in composite beams. Proceeding of ASCE SEI Structures Congress, eds M. Ingraffea \& M. Libby, ASCE: Portland, OR, pp. 876-887, 2015. https:/doi.org/10.1061/9780784479117.075

[6] Uy, B., Patel, V.I. \& Li, D., Behaviour and design of connections for demountable steel and composite structures. Keynote, 11th International Conference on Advances in Steel and Concrete Composite Structures, Tsinghua University, Beijing, China, December 3-5, 2015. https:/doi.org/10.1016/j.istruc.2016.06.005

[7] Ahmed, E., Badaruzzaman, W.W. \& Wright, H.D., Two-way bending behavior of profiled steel sheet dry board composite panel system. Thin-walled Structures, 40(11), pp. 971-990, 2002. https:/doi.org/10.1016/S0263-8231(02)00039-3

[8] Schaad, J., Two-way Steel Floor System Using Open-Web Joists (Thesis), Marquette University, Milwaukee, WI, 2005.

[9] Bernstein, H.M., Gudgel, J.E. \& Laquidara-Carr, D., Prefabrication and modularization: Increasing productivity in the construction industry. Smart Market Report, McGrawHill Construction NIST, 2011.

[10] International Code Council. 2015 International Building Code. Country Club Hills, Ill: ICC, 2015.

[11] Timoshenko, S.P. \& Woinowsky-Krieger, S., Theory of Plates and Shells, McGraw-hill: New York, Toronto and London, 1959.

[12] AISI-S100-12. North American Specification for the Design of Cold-Formed Steel Structural Members, American Iron and Steel Institute, Washington, DC, 2012. 
[13] DSS. Abaqus FEA version 6.14 documentation collection. Providence, RI: Dassault Systemes Simulia Corp, 2014.

[14] SSMA. Product Technical Guide. Steel Stud Manufacturers Association, 2015.

[15] HILTI. Direct Fastening Technical Guide 2015. North American Product Technical Guide. Ed 15, pp. 161-167, 2015. 